\title{
UNA TEORÍA BIOLÓGICA DE LA LIBERTAD
}

\author{
Juan Arana. Universidad de Sevilla
}

Joaquín M. Fuster, Cerebro y libertad. Los cimientos cerebrales de nuestra capacidad para elegir, Barcelona, Ariel, 2016. 375 pp.

Este libro de Joaquín Fuster prolonga una tradición que honra a la cultura española: la de los médicos-humanistas, tradición que podríamos remontar quién sabe si hasta Averroes y que pasando por Huarte de San Juan rebrotaría en el siglo XIX con Letamendi o Nieto Serrano y ya, en el siǵlo XX con nombres tan eximios como Ramón y Cajal, Marañón, Laín Entralgoo, Rof Carballo, López Ibor y más recientemente Vallejo Nájera o Diego Gracia. Últimamente se tenía la impresión de que su impulso decaía, pero libros como el que hoy nos convoca nos hacen recobrar la confianza de que no es así. Fuster conjuga su excepcional calidad y prestiǵio como científico con sus cultura y sensibilidad como humanista, reflejada, por ejemplo, en su brillante comentario del último movimiento de la cuarta sinfonía de Brahms (pp. 219-221). Y además es extraordinariamente valiente, pues aborda un tema conflictivo y espinoso donde los haya, como es el de la relación entre cerebro y libertad. Fuster no es ajeno a las importantes consecuencias que tiene en el campo de la vida individual y social, en el de la ética y la política, incluso en el de la cultura, el arte y la creatividad. Por eso dedica la segunda parte del libro a analizar la incidencia del problema de la libertad en todos esos ámbitos, parte que se convierte en un canto en defensa de la democracia y la tolerancia. Por supuesto que somos muchos los que compartimos con él la creencia en esos valores y la firme decisión de defenderlos. Pero no tiene la misma importancia ni repercusión que la defensa provenga de un artista, un escritor o un filósofo - -y menos aún un ideólogo o un político-, que cuando la realiza un neurocientífico distinguido. La diferencia radica en hoy en día la neurociencia constituye un paradigma ascendente, es la ciencia de moda. La sociedad deposita en ella sus esperanzas, los gobiernos compiten para protegerla, los presupuestos de las agencias públicas la miman porque, en definitiva, todos se disputan su favor. Unos y otros 
declaran que éste va a ser el año, la década o el siǵlo del cerebro. El desvelamiento de sus misterios ha ocupado en el imaginario colectivo el lugar que antes se reservó al desciframiento del genoma o a la conquista de la Luna. El número de jóvenes brillantes que se ocupan de estudiarlo ha crecido exponencialmente y los descubrimientos que aportan se amontonan en las revistas de prestigio y acaparan los titulares de los noticiarios. En estas condiciones es difícil escapar a la tentación de prepotencia y no sucumbir a la soberbia intelectual. El hecho de que vayan cayendo barreras y disipándose enigmas suscita en muchos la creencia de que no habrá obstáculo que se resista ni interrogante que quede sin aclarar. En el pasado ya pasó algo parecido con otras ciencias: la mecánica, le teoría electromagnética, la química orgánica, la biología evolucionista y más tarde la biología molecular alentaron en su momento la esperanza de que acabarían apagando toda la sed de saber del hombre y dispensando todas las gracias que éste puede anhelar. Incluso proyectos teóricos de menor envergadura, como la sociología de Durkheim, el psicoanálisis de Freud, el conductismo de Skinner, o el estructuralismo de Lévi-Strauss, Foucault o Lacan tuvieron su momento de gloria y concitaron pretensiones de dominio despótico sobre todas las ramas del saber y del hacer.

Es comprensible, pues, que representantes destacados de la neurociencia, junto con científicos de otras ramas atraídos por ella, filósofos igualmente motivados y comunicadores que no se quieren quedarse atrás lancen sin el menor recato todas las campanas al vuelo. Como ejemplos del primer colectivo cabe mencionar el libro: El cerebro y el mito del yo de Rodolfo Llinás; del segundo, La búsqueda científica del alma de Francis Crick; del tercero La conciencia explicada de Daniel Dennett; del cuarto, El alma está en el cerebro de Eduardo Punset. No obstante, hubo y hay neurocientíficos reticentes a extrapolar alegremente sus conclusiones olvidando las cautelas que el método científico aconseja. Las figuras de Sherrington, Penfield o el mismo Sperry en las generaciones pasadas, y Benjamin Libet o Giacomo Rizzolatti en la más reciente muestran contención, frente a la excesiva confianza y (según se mire) optimismo de los Edelman, Tononi, Changeux, Ramachandran, Damasio, Koch, Goldberg, etc.

Un rasgo que comparten los que sostienen que la neurociencia es o será una expendedora de verdades definitivas acerca del hombre es la 
actitud quitar importancia a los indicios de que la comprensión racional de la realidad natural tiene sus límites, tal como se ha descubierto en zonas más asentadas de la investigación, como la mecánica cuántica o la dinámica de sistemas complejos. Muchos autores prefieren ignorar tales señales de alarma, con la excusa de que, como gráficamente expresa Dennett: "en el cerebro, los efectos e indeterminaciones cuánticas se cancelan". Rubia es otro de los que piensan que para investigar el cerebro bastan y sobran las teorías físico-químicas que estaban vigentes a fines del siglo XIX, cuando aún no habían abandonado el determinismo. Es manifiesto que Joaquín Fuster no incurre en procedimientos tan confiados, por no decir descuidados. El reloj de su física está puesto en hora y toma buena nota de lo que podríamos denominar "límites intrínsecos" de la comprensión natural del mundo, cerebro incluido:

Esta postura está enfrentada a la neurociencia moderna por varias razones, entre ellas la complejidad, la varianza, la no linealidad y la naturaleza probabilística de las transacciones neurales, en especial con respecto a los fenómenos psicológícos (24).

No sólo conoce y asume la más reciente racionalidad científica, sino que se apoya precisamente en ella para dibujar un modelo de comprensión en el que los procesos neurológicos y la libertad, lejos de estar en conflicto, se diría que cooperan. Según sus propias palabras:

Sin embargo, es precisamente en el crisol de probabilidades e incertidumbres del cerebro humano donde cobra vida la libertad. La capacidad para escoger entre posibilidades proviene literalmente de la varianza y los grados de libertad de innumerables variables que subyacen a la acción humana futura. Como pasa con la evolución, el determinismo y la causalidad directa se disuelven en la probabilidad y, al hacerlo, ceden ante un factor teleológíco: la finalidad, el objetivo (17).

Hay, en efecto, un claro contraste entre el modo como afrontaba la comprensión de la actividad cerebral el determinismo neural y cómo lo hace Fuster: aquél procuraba estrechar los procesos causales hasta 
hacerlos prácticamente lineales; unas pocas neuronas o nodos canalizarían la toma de decisiones y explicarían la memoria o la toma de conciencia. Fuster, en armonía con los más recientes resultados de la investigación, acentúa su carácter relacional, destaca que las funciones de la mente se distribuyen en extensas zonas no sólo de la corteza cerebral, sino de estructuras subyacentes enraizadas a su vez con el entorno somático y cultural, lo que le lleva a otorgar un sentido nuevo al lema orteguiano "yo soy yo y mi circunstancia". Todo ello representa una bocanada de aire freseo que contribuye a despejar la enrarecida atmósfera del naturalismo al uso. La imagen que propone tanto del cerebro como de la libertad es más flexible y promisorio que lo que estamos acostumbrados quienes leemos con alguna asiduidad la literatura publicada en los últimos años sobre el particular. No obstante, Fuster deja muy claro que su aportación sigue apegada a la óptica naturalista, pues, como afirma repetidas veces:

Ello no equivale a considerar que alguna estructura cerebral, ni siquiera la corteza de los lóbulos frontales, escape a la causalidad natural o esté dotada de poder para elegir y decidir por nosotros. Más bien al contrario: entiendo que la dinámica de los lóbulos frontales está determinada en última instancia por el genoma y el entorno (13).

En este sentido, yo diría que Fuster es naturalista, pero no cientificista. El cientificismo implica convertir la ciencia natural en la instancia suprema para dirimir las preguntas que se refieren no sólo a la física, la química o la biología, sino también a la psicología, la sociología y en general a cualquier ciencia antropológica. Suele defender un reduccionismo por lo menos ontológico: no existen entidades con propiedades que vayan más allá de las que la ciencia detecta y estudia. En lo metodológico, acepta que las ciencias más particulares (como la neurociencia) trabajen con conceptos y métodos que no pertenecen a las ciencias más abarcativas (como la física), pero exige que por lo menos en principio haya la posibilidad de redefinir y unificar todos ellos bajo el patrocinio de éstas últimas.

El naturalismo no cientificista que atribuyo a Fuster deja a un lado el sueño de una ciencia unificada bajo patrones fisicalistas, pero insiste en que la reflexión filosófica aborde la síntesis de todos nuestros 
saberes sin mezclar en ella ingredientes diferentes de los que cada una de las ciencias, desde las más universales a las más particulares, contemplan.

Tengo que advertir que yo no me adhiero ni al naturalismo cientificista ni al que no lo es. Hay filósofos que se oponen al naturalismo en todos los terrenos. No pretendo hablar en su nombre, porque sí me apunto al naturalismo tanto en el campo de la naturaleza inorgánica como en el de la viva. Pero defiendo que en el paso de la vida no consciente a la consciente hay un salto categorial, que cierra el paso a una explicación de esta última desde los mismos principios explicativos que sirven para la primera. Considero que Fuster lo entiende de otra manera, y por eso defiende con bastante nitidez que la conciencia es una realidad exclusivamente derivada, un simple epifenómeno:

La experiencia consciente es por definición un fenómeno, o más exactamente un epifenómeno, en el sentido de que simplemente acompaña al estado y las funciones del cerebro. En cualquier caso, sí existe, pero carece de características (44)...

¿En qué consistiría entonces, concretamente? Veamos lo que dice Fuster:

La conciencia es un estado o cualidad de la mente funcional que sólo está presente - aunque desde el punto de vista operativo no es algo esencialen circunstancias de actividad mental relativamente intensa (99).

Quitar protagonismo a la conciencia es, por supuesto, una decisión teórica relevante que tiene graves consecuencias. Aunque no se diga expresamente equivale a separarla de las cosas que "son" para colocarla junto a las que simplemente "aparecen", lo cual no dista mucho de convertirla en mera fantasmagoría. La conciencia arrastra también consigo hacia el exilio al "sujeto", el "yo" y cualquier otro elemento que pudiera amparar la conjugación del verbo "actuar" en primera persona. A Fuster no le tiempla la mano cuando se trata de efectuar esa dolorosa operación quirúrgica. La maniobra, en principio, resulta amenazante para el concepto mismo de libertad, puesto que ¿cómo 
cabe hablar de libertad sin que sea propiedad de un agente bien definido? Él no quiere impugnar la libertad, y en eso consiste la oriǵinalidad de su aportación, que consiste en mantener la idea de libertad, aunque sin radicarla en la conciencia ni en el yo. ¿Dónde entonces? La respuesta es inequívoca: Fuster trasfiere la titularidad del concepto al cerebro mismo o, con mayor precisión, a la corteza cerebral prefrontal:

Para comprender cómo se toman las decisiones de información y acción en este inmenso archivo relacional que es la corteza humana, hemos de realizar dos cambios difíciles aunque indispensables en nuestro pensamiento. El primero es transferir el papel del «elector libre» desde el ego o el yo a la corteza cerebral. El segundo consiste en despojar al ego o al yo de la autoconciencia de sus decisiones; en otras palabras, hacer que la conciencia sea, en buena medida, «opcional» (125).

Lo que en definitiva propone Fuster es nada menos que "una explicación realmente biológica sobre la libertad humana" (268). Esto le sitúa, dentro de las clasificaciones que tanto nos gustan a los filósofos en el grupo de los compatibilistas. Compatibilista a propósito de la libertad y epifenomenista en lo que respecta a la conciencia. Los compatibilistas no creen que haya que renunciar a explicar la conducta humana en términos de causalidad natural para poderle atribuir simultáneamente libertad. Solían ser deterministas y concebían la libertad como conocimiento y aceptación de la necesidad, al modo de los estoicos y los espinozianos. Pero Fuster, ya lo he dicho, no es determinista, como tampoco lo es la ciencia contemporánea, la cual hace tiempo renunció a la idea de determinar por completo procesos tan complejos y escasamente unívocos como los que tienen lugar en la intrincada red neuronal que forma la entraña del cerebro. Un humanista como yo extrae de ello la conclusión de que la causalidad natural no ostenta la exclusiva de la determinación de todos los procesos que tienen lugar en el mundo en general y en el cerebro humano en particular. Por consiguiente, sin necesidad de homúnculos ni sustancias separadas, la realidad "hombre" cumple por un lado con todos los requisitos y consecuencias de la causalidad natural, sin dejar de ser protagonista en algún sentido de algún aspecto de lo que le pasa, lo 
cual aflora a nivel fenoménico en los procesos conscientes de decisión. Pero Fuster no pretende hablar de este tipo de libertad, cuya existencia considera en algún pasaje de su libro - y con cierto deje despectivouna cuestión meramente académica:

A estas alturas confío en haber ayudado al lector a llegar a la conclusión correcta de que la polémica sobre la existencia o no del libre albedrío, como un «todo o nada» absoluto, es algo puramente académico, irrelevante para la neurociencia (276).

Así pues, él quiere seguir hablando de la libertad en el plano de la neurociencia y, valga la redundancia, "liberar" la libertad de su encadenamiento al yo consciente. Así se explica que reivindique la posibilidad de considerar "libres" procesos mentales inconscientes:

...no somos conscientemente conscientes de las razones de gran parte de nuestra conducta. Esto no equivale a decir que nuestra conducta esté predeterminada y carezca de libertad (125).

...la libertad no necesita opciones conscientes (129).

...por lo general se supone que el libre albedrío conlleva conciencia, cuando quizá no sea así (150).

Las acciones propiamente dichas no se originarán en la conciencia, sino al revés. El agente será la corteza, y la conciencia será un subproducto de la acción (284).

Se acostumbra a asociar conciencia y libertad hasta el punto de exonerar de cualquier responsabilidad ética o penal los actos que uno haya podido cometer inconscientemente. ¿Por qué motivo? Porque se considera que al hacernos conscientes de nosotros mismos nos apropiamos de nuestra conducta y de nuestro ser. El uso corriente de la vOZ "libre" implica que lo libremente mío no se puede imputar a otra entidad y en cambio sí se puede -incluso se debe- atribuir al sustantivo al que el adjetivo en cuestión se adhiere. Esto es algo que tienen claro hasta los esquizofrénicos, cuando endosan la responsabilidad de 
cosas que han hecho a voces interiores pero extrañas que las ordenaron.

Hay por lo tanto en el concepto de libertad una dimensión negativa y otra positiva. La negativa se suele interpretar como "ausencia de coacción ajena", tanto externa como interna, y en este sentido se dice que soy libre de esto o de aquello, o que un animal es libre cuando no está encerrado dentro de una jaula, ni tampoco tiene electrodos insertados en su cerebro que mediaticen su comportamiento espontáneo. Podríamos llamar a esta libertad "libertad de" (libertad de ir al cine, de seguir bestiales instintos, de sacrificarse por un alto ideal...). Pero la noción no acaba de definirse si junto la libertad meramente negativa ("de qué cosa") no añadimos explícita o implícitamente una libertad positiva o "de qué agente", es decir, de qué sujeto o al menos de qué factor determinante proviene la decisión le atribuimos. En otras palabras: se trata de identificar la instancia desde la que se ha dicho la última palabra.

El libro de Fuster tiene el empeño de buscar una alternativa creíble dentro del horizonte de la neurociencia a la conciencia, el yo, el alma o cualquier otra noción extraña a dicha disciplina. La conciencia por cierto que no lo es, pero - al parecer y según el criterio de Fusterlo sería si llegara a independizarse convirtiéndose en algo más que un epifenómeno. A su juicio hay una única solución: el genuino poseedor de la libertad sería el cerebro o al menos la parte de él más directamente involucrada en el procesamiento de la información y la génesis de respuestas, o sea, la corteza prefrontal.

...el albedrío humano es un fenómeno de la capacidad del cerebro para escoger, racionalmente o no, entre diversas acciones posibles (11).

...muchos estudios experimentales confirman que la corteza prefrontal ejerce un supuesto control cognitivo-ejecutivo sobre una amplia variedad de estructuras cerebrales corticales y subcorticales, con la finalidad de agudizar la atención, mantener la memoria de trabajo, tomar decisiones y organizar acciones con objetivo (41).

La que es libre es nuestra corteza (49n). 
El albedrío es tan libre como lo es la corteza para seleccionar acciones futuras y prepararse para ellas (75).

Todo ello está muy bien, o al menos resulta muy claro, pero es difícil evitar que, al endosarle como atributo la libertad, el cerebro en general y la corteza prefrontal en particular se contaminen de las funciones rectoras y cuasi sustanciales que antaño se reconocían al alma, la subjetividad o la conciencia. En otras palabras: la tendencia natural de una corteza cerebral libre, liberada o/y liberadora es a "homunculizarse", como sagazmente detecta Fuster:

Si otorgamos a la corteza prefrontal el papel de ejecutivo supremo, entonces la cuestión es a qué otro «controlador» o «autoridad» —entidad cognitiva o estructura cerebral - obedece la corteza prefrontal; y podríamos formular la misma pregunta acerca de dicha autoridad, y así ad infinitum (42).

Ahora bien: una cosa es detectar un peligro y otra muy distinta conjurarlo. Para evitar que una entidad con claro sentido funcional y anatómico, como la corteza se convierta en algo así como un motor inmóvil, una causa primera o "un gancho colgado del cielo", de acuerdo con la expresión que le gusta usar a Daniel Dennett, no veo que Fuster haga mucho más que prohibírselo:

Quiero establecer una distinción clara entre la idea simplista de la corteza prefrontal como un mítico «ejecutivo central en el cerebro», cosa que no es, y su papel fundamental en la concepción y la organización de acciones con objetivo (13-14).

El libro es coherente con este propósito, puesto que no apela a otras funciones que las que la técnica experimental neurocientífica aporta: vías nerviosas que constituyen sus entradas y salidas, mecanismos de descargas neuronales, de liberación y eaptación de neurotransmisores, importancia de la mielinización, etc. etc. Es una estructura densamente interconectada consigo misma y con su entorno, sin barreras que la separen del resto del cerebro, el sistema nervioso y hormonal, el soma y en definitiva el mundo. Si no actúan en 
ella factores alternativos a la causalidad natural, ¿qué prerrogativa ontológica o funcional permite generar y mantener el fenómeno de la libertad? Me temo que no quedan otras alternativas que apelar a un holismo con virtudes taumatúrgicas o dar al azar capacidades igualmente miríficas, como de alguna manera hizo Jacques Monod en su momento. Con todos los respetos para estas opciones, que en todo caso exigirían un desarrollo específico, opino que la libertad merece y exige mucho más.

Juan Arana

jarana@us.es 